\title{
Engajamentos locais, práticas globais: consciência e ação de uma jovem carioca, cidadã do mundo
}

\author{
Renato Pontes Costa ${ }^{1}$ \\ Erica Nascimento ${ }^{2}$ \\ José Elesbão Duarte Filho ${ }^{3}$
}

\section{Introdução}

\author{
A vida não é para ser útil. Isso é uma besteira. \\ A vida é tão maravilhosa \\ que a nossa mente tenta dar uma utilidade para ela. \\ A vida é fruição. A vida é uma dança. \\ Só que ela é uma dança cósmica \\ e a gente quer reduzi-la a uma coreografia ridícula e utilitária, \\ a uma biografia: alguém nasceu, fez isso, fez aquilo, \\ fundou uma cidade, inventou o fordismo, fez a revolução, \\ fez um foguete, foi para o espaço... \\ Tudo isso, gente, é uma historinha tão ridícula! \\ A vida é mais do que tudo isso. \\ Nós temos de ter coragem de ser radicalmente vivos. \\ E não negociar sobrevivência.
}

(Ailton Krenak)

Vivemos um tempo de muitos desafios e grandes exigências. A pandemia do novo coronavírus desencadeou, a partir do início do ano de 2020, uma série de tensionamentos que desestabilizaram diversos âmbitos da vida humana. Mas a vida, como indicam as palavras de Ailton Krenak na epígrafe deste artigo, "é muito mais que tudo isso", então, "não podemos negociar a sobrevivência". Como fruição e dança cósmica, nossa humanidade é sempre capaz de se reinventar diante das dificuldades e construir alternativas em busca de "ser mais".

A pandemia é uma enorme questão que nos atravessa nesse momento da história, mas ela não é a única ameaça que a humanidade enfrenta. O mundo contemporâneo, desde a década de 1980, experimenta diversas transformações e reinvenções do capitalismo que igualmente colocam à prova a vida e a existência da humanidade em muitas dimensões (SANTOS, 2020).

1 Licenciado em Filosofia, Mestre em Educação Brasileira (2001) e Doutor em Ciências Humanas - Educação (2018), pela Pontifícia Universidade Católica do Rio de Janeiro. Atualmente é professor do Departamento de Educação da PUC-Rio. e nessa universidade foi um dos fundadores do NEAd - Núcleo de Educação de Adultos da PUC-Rio, onde atuou por 15 anos. Tem experiência na área de Educação, com ênfase em Educação de Jovens, Adultos, Educação Popular, Educação em Direitos Humanos e Produção de Materiais Didáticos.

2 Pedagoga (2015) e Mestra em Educação (2021) pela Pontifícia Universidade Católica do Rio de Janeiro. Educadora em/para Direitos Humanos, tem experiência docente na área do Ensino Fundamental I e II. Participou do Programa de Intercâmbio Acadêmico na Universidad Autônoma de Madrid - Espanha (2014). Atualmente é integrante do Grupo de Estudo sobre Cotidiano, Educação e Culturas (GECEC-PUC/Rio). Pesquisa juventudes, processos formativos e decolonialidade/interculturalidade.

3 Bacharel em Direito (2004) e Licenciado em Filosofia (2018) pela Pontifícia Universidade Católica do Rio de Janeiro e atualmente é mestrando em Educação na mesma Universidade. Tem experiência como educador na área de Educação de Jovens e Adultos - EJA: atuação em projetos de alfabetização de adultos, de continuidades de estudos e de formação de professores. Possui ainda experiência em EaD, atuando como mediador pedagógico a distância no âmbito do Consórcio Cederj - Fundação CECIERJ, junto ao curso de Pedagogia da UERJ (2011 a 2020). 
A atual fase da revolução tecnológica, desdobramento de uma das revoluções industriais que estamos atravessando, vem provocando, por exemplo, mudanças cada vez mais significativas na maneira como os seres humanos se colocam no mundo. O capitalismo se modificou, mas não desapareceu. A exploração e a dominação, características desse modo de produção, se ampliaram e se camuflaram em formas outras de opressão que alguns autores já chamam de "capitalismo cognitivo" (MEJÍA JIMENES, 2020). Os problemas humanos há tempos deixaram de ser apenas locais e assumem dimensões planetárias exigindo de nós ações e respostas cada vez mais amplas. O cuidado com o outro hoje, significa o cuidado com todo o planeta e qualquer ação, por mais local que pareça, não se descola de uma reação global. Mas, se por um lado os desafios se ampliaram nas últimas décadas, também as iniciativas insurgentes se reconfiguram e passam a assumir uma amplitude que extrapola a sua realidade local. Por baixo do tecido social indivíduos e grupos subalternizados se organizam determinando ativismos emergentes antenados com as possibilidades que se desenham num mundo conectado.

Nos últimos anos mudanças importantes têm ressignificado formas de ação coletiva e protesto político por parte das juventudes. O trabalho de Sposito, Almeida e Corrochano (2020) observou uma tendência de constituição de ações em pequenos grupos como parte de um engajamento político dotado de criatividade e autonomia. De acordo com os autores há uma mescla entre a ideia de "trabalho de base" de décadas anteriores e o trânsito em ações de assistência, lazer e ativismo político (SPOSITO et al., 2020). Soma-se a essa tendência, as novas mídias sociais e uma ressignificação em teor propositivo sobre as realidades experimentadas e sonhos democráticos. Sujeitos e coletivos que transitam em pautas contra hegemônicas e acentuam-se enquanto microuniversos insurgentes mobilizando experiências, representações e proposições em postura planetária (NASCIMENTO, 2021).

É neste contexto que o trabalho busca dialogar e refletir a partir de processos de mobilização e engajamento político social. Para tal, visibilizamos a trajetória de uma das jovens que representa o Brasil no Youth20 ${ }^{4}$ de 2021. Por esta proposta micro referenciada destacamos (des)aprendizagens, sonhos democráticos e alguns aspectos das novas formas de ativismo juvenil. A proposta do artigo é então evitar a reflexão sobre um cidadão do mundo idealizado e impessoal. Queremos ampliar a lente e enxergar um pouco mais de perto práticas e colocações de uma jovem concreta e perceber a presença profética de sua atuação no mundo de hoje. Tal qual (FREIRE, 1979) partimos do ponto que presenças proféticas são aquelas que anunciam e

\footnotetext{
${ }^{4} \mathrm{O}$ Youth 20 é um fórum diplomático internacional onde jovens líderes discutem projetos globais com as 20 principais economias mundiais, o G20. O grupo de jovens selecionados é um compromisso oficial do G20. Em 2021 três jovens mulheres foram selecionadas para debater os temas da "Inovação, Futuro do Trabalho e Digitalização", "Inclusão" e "Sustentabilidade, Mudança Climática e Meio Ambiente". Em decorrência da pandemia de covid-19 este ano o evento será on-line.
} 
denunciam, comprometidos permanentemente num processo radical de transformação do mundo, para que os homens possam ser mais.

\section{Presença e percurso no mundo}

Em interlocução com a proposta da entrevista compreensiva difundida por Ferreira (2014), "entrevê-se", ou seja, dialoga-se permanentemente com, Lara Martins, 29 anos, mulher, negra, moradora da zona norte do Rio de Janeiro, publicitária, especialista em gerência de projetos do Sistema $\mathrm{B}^{5}$ e uma das três integrantes da delegação de jovens que representa o Brasil no Y20. Dentre os aspectos destacados no decorrer da entrevista, Lara rememora experiências educativas que, conforme suas reflexões, potencializaram e redimensionaram hesitações em proposições. Ao apresentar-se, a entrevistada valoriza experiências educativas em pontos referenciais refletidos em suas escolhas e posturas político sociais.

Na PUC também me destacava. Na área de comunicação você pode escolher qual área que você vai [atuar]. Eu estava super definida que eu ia pra publicidade. [...] Uma professora, Cláudia Chaves dizia: não! Lara vai ser diretora de uma grande empresa. [...] Aí então o pessoal falava, pega empreendedorismo e tal, aí eu falei: não, quero não! Mas alguém falava de uma professora e essa professora não era só uma pedagoga, era jornalista e psicóloga, doutora, e ela dava uma aula de planejamento de vida profissional - Sandra Korman, não sei se você conhece. Então, eu fiz a matéria dela. Além de me despertar pro intercâmbio, pra o que eu queria fazer, o que eu queria ser, o meu planejamento de vida; ela também me despertou pra fazer o domínio adicional de empreendedorismo, porque ela falou: não é que você queira ser empreendedora, você tem o perfil de empreendedora, você tem algumas habilidades e competências.

[...] eu acho que aprendi na PUC, como criar metas, acho que isso funcionou muito com o meu perfil metodológico, ambicioso, organizado, planejado.

Ao analisar sua trajetória, Lara faz dois destaques importantes na sua formação: a participação na disciplina Planejamento de Vida Profissional, com a professora Sandra Korman ${ }^{6}$ e a experiência do intercâmbio feito em 2014, em Madri, na Espanha. Segundo a entrevistada a participação na disciplina representou um desvio no seu percurso formativo, que possibilitou reflexão e projeção profundas sobre o seu futuro profissional. O intercâmbio possibilitou não só a ampliação do seu lugar de referência, já que as fronteiras se estenderam para além da realidade local, mas também certo direcionamento profissional e, aliado a isso, a ampliação de uma consciência social.

Então foi isso, acho que o ponto de virada foi a Sandra [Korman].

Eu sempre tive uma ligação com a natureza, e aí volto para a questão da importância do intercâmbio porque foi lá que eu conheci a questão de como que a gente pode consumir conscientemente. Eu volto pro Brasil e o meu TCC, com a Sandra Korman foi sobre consumo consciente. Peguei o lado da publicidade e

\footnotetext{
${ }^{5}$ Sobre o Sistema B - Brasil, consultar: https://www.sistemabbrasil.org/

${ }^{6}$ Sobre essa questão ver: KORMAN DIB (2006) e KORMAN DIB e CASTRO (2010).
} 
falei, a gente incentiva o consumo; [mas], tem como a gente, não deixar de incentivar (senão não faz sentido ser publicitária), mas incentivar o consumo consciente? Então fiz o meu TCC com a Sandra Korman sobre isso e a gente fez um trabalho final também em empreendedorismo que também foi sobre isso; sobre um projeto que eu fiz no intercâmbio. Então, aí a importância do intercâmbio... é que sempre fez sentido pra mim, sei lá, virou que meio uma chave pra mim [...] se eu for incentivar, eu vou incentivar alguma coisa que a gente consuma porque a gente precisa e não por exagero.

Neste desenvolvimento profissional, Lara constrói uma postura crítica no campo social e demonstra olhar prospectivo na construção de uma consciência planetária. Atualmente a entrevistada trabalha num movimento global que pensa a economia em bases outras, preocupadas com a dimensão humana das organizações, visando a "construção de um sistema econômico mais inclusivo, equitativo e regenerativo para as pessoas e para o planeta" (SISTEMA $B, 2021)$. Sua atuação profissional já demonstra uma releitura da sua própria formação, dando a ela um sentido não só humano, coletivo, mas também planetário.

Fiz Publicidade, Comunicação Social. Sou especialista em gerenciamento de projetos. Fiz MBA na Escola de Negócio [da PUC] e eu sou gerente de comunidades do sistema "B" Brasil, que é um movimento global que usa o poder das pessoas por meio dos negócios para... enfim... construir um mundo melhor, sabe, mais inclusivo, mais equitativo e tentar redefinir o conceito de sucesso na economia, né? Não é uma questão de competição e sim, uma questão de colaboração. Não é a melhor empresa do mundo e sim, a melhor empresa para o mundo. Então, a gente é uma ferramenta de mensuração de impacto positivo. As empresas respondem um questionário com muitas perguntas... perguntas de todos os benefícios: movimento " $B$ ", sistema "B", de benefícios que você oferece para seus empregados, para seus fornecedores, pra comunidade que você está inserido, pro meio ambiente, pros seus clientes.

Agindo nas brechas do sistema mundo excludente, Lara constrói uma projeção e se coloca como protagonista da história. Em diferentes momentos da entrevista, reconhece, que a educação é uma ferramenta importante para concretizar a sua inserção profissional, mas também para a construção de uma atuação consciente e conectada com problemas de ordem global.

Do Pedro II, por mais que seja um colégio de excelência, cinco foram estudar na PUC. O resto, todo mundo foi pra [Universidade] pública, isso porque a maioria passou, já teve um diferencial ali. Então, só de fazer pra PUC, conseguir intercâmbio, já tem umas brincadeiras... tipo, "eu sou super competitiva", então tem tipo... os amigos falam que eu vou dominar o mundo. Acho que também tive uma questão de oportunidade de entender o meu lugar, nesses espaços. Assim, pra falar, tipo, ah! Brasil... eu já falava outros idiomas. Eu ganhei prêmios de francês quando eu tava no Pedro II, né, no ensino fundamental, ensino médio. [...] Nunca achei que fosse uma questão de... Foi como um estalo que eu só tive a uns dois anos atrás [...] tem muito espaço para brasileiro, espaço para mulher, espaço para mulher negra. Então... tem uma vaga para mim aí, então eu vou me inscrever [...] não por cotas, mas por ser um diferencial, uma mulher negra que fala espanhol, uma mulher negra que fala francês. 
A entrevistada articula ações-práticas do seu pertencimento profissional com um engajamento social que a levam a uma dimensão ética maior para o agir no mundo e pelo mundo. O seu lugar de fala, de atuação, de competência específica como publicitária fazem com que Lara aventure-se em projetos que extrapolam e transcendem sua localização imediata e suas identidades de jovem, negra, periférica, etc. No sentido freireano, podemos dizer que Lara busca cotidianamente exercer a sua vocação de "ser mais" e entender/reconhecer que, como diz Freire (1995, p. 91) "trabalhar contra esta vocação é trair a razão de ser de nossa presença com o mundo".

Dentre suas motivações para participação no Y20 Lara reitera a pluralidade de sentidos objetivos e subjetivos de representar o que ela entende como "Sul Global"7.

Afinal, qual o objetivo do Y20? A ideia é que os grupos de jovens façam uma carta final com as propostas que os jovens acreditam [que] sejam importantes para trabalhar a economia de uma maneira saudável, e [esta carta] é entregue pra presidência do G20, os líderes das 20 maiores economias do mundo. [...] O Brasil tem que estar representado com as propostas dele, então o meu trabalho é fazer as minhas maiores alianças pra que as propostas que fazem sentido para o Brasil e que sejam prioritárias, estejam entre as 24 finais. E aí tem uma questão não só de aprovação de política pra realidade do Brasil. Eu estou defendendo o Brasil, tudo depende de mim, então, é uma questão estratégica. Por isso que as reuniões bilaterais [são relevantes], e aí mostra, de novo, a importância da educação, a importância do intercâmbio.

[...] todas as propostas do Sul Global são baseadas nos Direitos Humanos e aí... a gente... as que eu subi... e que tem agora que fazer aprovar, acordando com outras que estão aprovadas na mesma linha são:

1. Garantia de inserção de pelo menos $80 \%$ da força de trabalho jovem no mercado V.U.C.A. - Volatility, Uncertainty, Complexity, Ambiguity (Volatilidade, Incerteza, Complexidade e Ambiguidade), para reduzir as desigualdades;

2. Incentivar a pesquisa e a ciência como forma de desenvolver a qualidade de vida e o uso ético da digitalização;

3. Até 2028 promover o empreendedorismo juvenil como uma das múltiplas oportunidades de desenvolvimento econômico por meio da cooperação internacional.

\section{Presença e ânimo com o mundo}

Com e a partir das falas da entrevistada, é possível refletir sobre o agenciamento de pedagogias em perspectiva de ler a realidade e potencializar ações no mundo e para o mundo. Tais reflexões são especialmente pertinentes para visibilizar sujeitos jovens engajados em um mundo possível. Ao longo da entrevista Lara evidenciou na atuação de seus professores

\footnotetext{
${ }^{7}$ O Sul Global mencionado nesta entrevista aproxima-se do debate dos estudos pós-coloniais e refere-se ao conjunto de países da América Latina, África e Asia historicamente subalternizados. O termo obteve destaque com a obra do artista uruguaio Torres-Garcia com a pintura do "Mapa Invertido da América do Sul”, em 1943. A ilustração provoca a necessidade de notabilizar os processos de desenvolvimento e culturas silenciadas pela ideia colonial de modernidade presente no Norte Global, como Estados Unidos e países da Europa.
} 
concepções educacionais críticas e comprometidas com a transformação social. Concepções que se aproximam do que expressa Freire (1995, p 69) quando fala sobre:

\begin{abstract}
“(...), a impossibilidade total de ser neutros em face do mundo, do futuro - que não entendo como um tempo inexorável, um dado dado, mas como um tempo a ser feito através da transformação do presente com que se vão encarnando os sonhos -, nos coloca necessariamente o direito e o dever de nos posicionar como educadores. $\mathrm{O}$ dever de não nos omitir. $\mathrm{O}$ direito e o dever de viver a prática educativa em coerência com nossa opção política."
\end{abstract}

É essa educação que Lara reconhece como capaz de gerar uma transformação no mundo.

Não estou puxando a sardinha pro lado de vocês, mas é isso, referência em todos os meus professores, sou amiga de professores [...] mas é a educação, pra resolver o problema da questão ambiental que é o que eu trabalho, resolver o problema da desigualdade, pra resolver o problema da inovação, futuro do trabalho e digitalização, clima; é educação.

Retomando a sua trajetória Lara faz um elogio à educação - "um futuro só é possível por meio da educação; eu só sou possível por meio da educação". Para a entrevistada, as experiências educativas que teve e os aprendizados que acumulou possibilitaram conhecimentos significativos para consolidar opções e ações propositivas. Mobilizaram também perspectivas para além da realidade imediata capazes de ajudar a ampliar o olhar para o mundo. A consciência que se formou nas experiências educativas e nas opções engajadas de atuação profissional foi capaz de mantê-la enraizada na sua realidade local, mas sempre tensionada a pensar um "universo" mais amplo e melhor; a refletir sobre as "barreiras" sociais e políticas que o mundo contemporâneo estabelece e a desenhar formas de ultrapassar essas barreiras.

Essa educação, com certeza, não foi qualquer educação. Lara encontrou no seu caminho educadores que atuavam (talvez mesmo sem ter consciência disso) na direção daquilo que Paulo Freire descreve como o "educador progressista", ou seja, aquele que lê o seu tempo e constrói no processo, um olhar prospectivo e coletivo para a realidade social.

O educador progressista não pode aceitar nenhuma explicação determinista da História. O amanhã para o educador progressista não é algo inexorável. Tem de ser feito pela ação consciente das mulheres e dos homens enquanto indivíduos e classes sociais. A libertação não virá porque a ciência preestabeleceu que ela virá. A libertação se dá na História e se realiza como processo em que a consciência das mulheres e dos homens é um sine qua. Neste sentido, a natureza ética desta luta política tem tal importância que não pode ser menosprezada o mais mínimo que seja. Freire (1995, p.92) 
Essa educação tem um sentido cíclico como aponta a entrevistada. A cidadã do mundo que se tornou Lara não perde de vista a sua origem, a sua identidade e fala no retorno social que sua ação pode gerar para o conjunto da sociedade brasileira.

Sou muito grata à minha $2^{a}$, $3^{a}$ mãe, né, eu sou filha da PUC, que bom que eu posso tá retornando alguma coisa [...] então, quando eu tô representando o país, eu também tô tentando retornar alguma coisa da minha educação que foi pública, ou então que foi bolsista integral na PUC, né. É um pouco do meu retorno pra tudo que recebi.

Nesse sentido, é possível afirmar que Lara se aproxima da máxima de que educar não é apenas instruir, mas viver experiências significativas. Essa educação viva que nos provoca é mobilizada através de diferentes dimensões, mas fundamentalmente pela formação intelectual e pela construção de laços afetivos. No caso de Lara, foi a dimensão afetiva que envolveu cada uma de suas escolhas e o reconhecimento das oportunidades que the colocaram em contato com uma realidade global; e a dimensão intelectual, que lhe possibilitou um olhar crítico e um agir propositivo diante da estrutura política na qual está inserida. Em última análise, a trajetória de Lara realça elementos que corroboram com a importância da formação humana e acadêmica na promoção de ações éticas, participativas, comprometidas, engajadas na perspectiva de um mundo melhor. Isso significa estar consciente da posição estratégica que se ocupa na estrutura social mundial e construir caminhos de intervenção desde o seu lugar, pois como diria Freire (1979, p. 15) "a conscientização não está baseada sobre a consciência, de um lado, e o mundo, de outro; por outra parte, não pretende uma separação. Ao contrário, está baseada na relação consciência - mundo." Trata-se, pois, da efetiva inserção e compromisso com o papel do cidadão na sociedade planetária.

\section{Questões:}

1. Quais aspectos você destacaria como mais fundamentais na trajetória de Lara? Em que dimensões a trajetória dessa jovem cidadã do mundo te inspira?

2. Quais situações você se pensa agindo localmente em consideração às questões planetário? Ou o contrário, ao reconhecer uma questão global, como você age localmente?

3. O Texto nos desafia pensar sobre o chamado "consumo responsável". Qual a sua posição em relação a essa questão e como você acha que ela se relaciona com a sobrevivência do planeta? De que maneira você entende e pratica o consumo responsável?

4. Se você tivesse que apresentar uma pauta de proposições para os representantes das 20 maiores economias do mundo, qual seria a sua proposta? 


\section{Referências}

FERREIRA, V. S. Artes e manhas da entrevista compreensiva. Saúde e Sociedade, v. 23, n. 3, p. 118-130, 2014.

FREIRE, P. Política e educação. - $2^{2}$ edição - São Paulo: Cortez, 1995. (Coleção questões de nossa época: v. 23).

FREIRE, P. Conscientização: teoria e prática da libertação: uma introdução ao pensamento de Paulo Freire. São Paulo: Cortez \& Moraes, 1979.

KORMAN DIB, S. e CASTRO, L. R. de. O trabalho é projeto de vida para os jovens? Cadernos de Psicologia Social do Trabalho, 2010, vol. 13, n. 1, pp. 1-15.

KORMAN DIB, S. Juventude e projeto profissional: a construção subjetiva do trabalho. Tese de Doutorado. Rio de Janeiro: UFRJ/IP, 2006.

MEJÍA JIMÉNEZ, M. R. Educación(es), escuela(s) y pedagogía(s) en la cuarta revolución industrial desde Nuestra América - Tomo III. Bogotá: Ediciones desde abajo, 2020.

NASCIMENTO, E. P. dos S.; CANDAU, V. M. A contribuição dos saberes-fazeres na trajetória de jovens ativistas gonçalenses. Rio de Janeiro, 2021. 146p. Dissertação de Mestrado Departamento de Educação, Pontifícia Universidade Católica do Rio de Janeiro.

SANTOS, B. de S. A cruel pedagogia do vírus. Coimbra: Edições Almedina S.A., 2020.

Sobre o movimento B. Sistema B, Brasil, 2021. Disponível em: <https://www.sistemabbrasil.org/>. Acesso em: 13, jul/2021.

SPOSITO, M. P.; ALMEIDA, E. de; CORROCHANO, M. C. Jovens em movimento: mapas plurais, conexões e tendências na configuração das práticas. Educação e Sociedade, v. 41, p. 1-20, 2020. 